\title{
Maternal and Perinatal Outcome of Threatened Abortion with Subchorionic Hemorrhage in First and Second Trimester
}

\author{
Bhagirathi Kayastha, ${ }^{1}$ Abha Shrestha, ${ }^{2}$
}

'Department of Obstetrics and Gynecology, College of Medical Sciences, Chitwan, Nepal ${ }^{2}$ Department of Obstetrics and Gynecology, Dhulikhel Hospital, Dhulikhel, Nepal

\section{ABSTRACT}

\section{Introduction}

Threatened abortion with subchorionic hemorrhage $(\mathrm{SCH})$ is a common phenomenon during first and second trimester of pregnancy. Most pregnancies may continue to term and may be associated with poor maternal and fetal outcomes. The objective of this study was to assess the maternal and perinatal outcomes of threatened abortion with $\mathrm{SCH}$ in first and second trimester.

\section{Methods}

This prospective study was conducted in Dhulikhel Hospital from August 2017 to July 2018. Total 150 cases were included in the study who had ultrasonography done to find out the size of $\mathrm{SCH}$. They were followed up until spontaneous abortion or up to delivery of fetus. The outcomes were documented in terms of abortion, antepartum hemorrhage (APH), term or preterm vaginal delivery, cesarean section, intrauterine growth restriction (IUGR), low birth weight (LBW) and neonatal intensive care unit (NICU) admission.

\section{Results}

The mean age was $25.39 \pm 5.60$ years and $59.33 \%$ were primigravida. $82.66 \%$ had SCH of size $<4 \mathrm{~cm}^{2}$ and rest had $\mathrm{SCH}$ of size $\geq 4 \mathrm{~cm}^{2} .9 .33 \%$ had spontaneous abortion. Among those whose pregnancy continued, $11.75 \%$ had preterm delivery, $14.70 \%$ had $\mathrm{APH}, 18.38 \%$ had IUGR, $11.76 \%$ had LBW and $13.97 \%$ had NICU admission.

\section{Conclusions}

The size of SCH influences the pregnancy outcomes. Spontaneous abortion was seen more with $\mathrm{SCH}$ of size $\geq 4 \mathrm{~cm}^{2}$ whereas continuation of pregnancy was seen more with $\mathrm{SCH}$ of size $<4 \mathrm{~cm}^{2}$. The associations of $\mathrm{SCH}$ of size $\geq 4 \mathrm{~cm}^{2}$ with APH and IUGR were found to be significant whereas those with NICU admission and LBW were found to be insignificant.

Keywords: Maternal and perinatal outcomes; subchorionic hemorrhage; threatened abortion; ultrasound

Correspondence: Dr. Bhagirathi Kayastha, Department of Obstetrics and Gynecology, College of Medical Sciences, Chitwan, Nepal. Email : kayakayastha@gmail.com. Phone: +977-9841439879. 


\section{INTRODUCTION}

Threatened abortion is the most common complication of pregnancy occurring in 20-25\% of ongoing pregnancy. It is diagnosed on the basis of documented fetal cardiac activity on ultrasonography (USG) with history of vaginal bleeding in the presence of closed cervix. ${ }^{1} \mathrm{USG}$ may show subchorionic hemorrhage ( $\mathrm{SCH}$ ) of varying size, defined as a crescent shaped echo free area outlining the intact gestational sac. ${ }^{2}$

Bleeding during pregnancy can cause maternal anxiety and may be associated with poor fetal outcomes like preterm delivery, low birth weight (LBW), intrauterine growth restriction (IUGR) and neonatal intensive care unit (NICU) admission whereas poor maternal outcomes include increased risk of abortion, pre-labor rupture of membrane (PROM) and antepartum hemorrhage $(\mathrm{APH}){ }^{3}$

The main objective of this study was to identify the maternal and perinatal outcomes in threatened abortion with subchorionic hemorrhage so that they can be managed earlier to reduce the morbidity and mortality.

\section{METHODS}

This prospective longitudinal study was conducted in the Department of Obstetrics and Gynecology, Dhulikhel Hospital (DH) -Kathmandu University Hospital from August 2017 to July 2018. Ethical approval was obtained from the Institutional Review Committee (IRC) of KUSMS. Convenient sampling method was used for data collection.

The sample size was calculated using the following formula (Cochran formula)

Sample size $(\mathrm{N})=(\mathrm{Z})^{2}{ }^{*} \mathrm{P}(1-\mathrm{P}) / \mathrm{M}^{2}$

$$
\begin{aligned}
& =(1.96)^{2 *} 0.11(1-0.11) /(0.05)^{2} \\
& =150.43
\end{aligned}
$$

Where, $Z=$ degree of confidence level at 95\%= 1.96 $\mathrm{P}=$ Prevalence of the disease $(11 \%), \mathrm{M}=$ Margin of error i.e. $5 \%$

Predesigned questionnaire was used in order to collect the necessary information.

All women of age 16 to 40 years with singleton live intrauterine gestation with subchorionic hemorrhage as seen on ultrasonography done in between 6 and 28 weeks of gestation, attending the antenatal outpatient department with per vaginal bleeding were considered for the study. After excluding women with history of hypertension, diabetes, renal disorder, multifetal pregnancy, uterine fibroid or cervical pathology like polyp and erosion, congenital uterine anomaly, cervical incompetence and pregnancy failure diagnosed on the first visits, total of 150 women were included in this study.

After proper counseling, informed consent was taken from each patient. The history, physical examination, and relevant laboratory investigations were done. The blood investigations included complete blood count, bleeding time, clotting time and platelets. Routine and microscopic examination of urine was done.

Management included complete bed rest up to 72 hours, folic acid supplementation, low dose aspirin, phenobarbitone and injection human chorionic gonadotrophin (HCG) weekly up to 12 weeks and injection $17 \alpha$ hydroxyprogesterone after 12 weeks was given weekly up to 28 weeks. Follow up of the patient was done till spontaneous abortion or up to delivery of fetus.

Maternal outcomes were measured in terms of spontaneous abortion, term or preterm vaginal delivery and Cesarean section (CS). Perinatal outcomes were measured in terms of preterm birth, IUGR, LBW, and NICU admission.

The collected information was entered in Microsoft Excel 2016. The data were analyzed using Statistical Package for Social Science (SPSS), version 16. The Chi-square test, Fisher exact test 
Kayastha et al. Maternal and Perinatal Outcome of Threatened Abortion with Subchorionic...

and Likelihood ratio were used to find out the significance of the study parameters. The p-value $<0.05$ was considered significant.

\section{RESULTS}

Table 1. Demographic data

\begin{tabular}{|l|l|}
\hline Age (Mean \pm SD)years & $25.39 \pm 5.60$ \\
\hline Nulliparity $(n, \%)$ & $89,59.33 \%$ \\
\hline Multiparity $(n, \%)$ & $61,40.67 \%$ \\
\hline Gestational age (Mean \pm SD) weeks & $14.84 \pm 5.60$ \\
\hline
\end{tabular}

Table 2. Size of subchorionic hemorrhage with pregnancy outcomes

\begin{tabular}{|l|l|c|l|c|}
\hline \multirow{2}{*}{$\begin{array}{l}\text { Size of } \\
\text { subchorionic } \\
\text { hemorrhage }\end{array}$} & \multicolumn{2}{|c|}{$\begin{array}{c}\text { Spontaneous } \\
\text { Abortion }\end{array}$} & \multicolumn{2}{c|}{$\begin{array}{c}\text { Continuation of } \\
\text { pregnancy }\end{array}$} \\
\cline { 2 - 5 } & Frequency & $\%$ & Frequency & $\%$ \\
\hline$<4 \mathrm{~cm}^{2}$ & 10 & $8.06 \%$ & 114 & $91.93 \%$ \\
\hline$\geq 4 \mathrm{~cm}^{2}$ & 4 & $15.38 \%$ & 22 & $84.61 \%$ \\
\hline
\end{tabular}

Out of 150 cases, 8.06\% (10) had spontaneous abortion after diagnosis of threatened abortion and $91.93 \%$ (114) continued after 28 weeks of gestation in $<4 \mathrm{~cm}^{2} \mathrm{SCH}$ whereas $15.38 \%(4)$ had spontaneous abortion and $84.61 \%$ continued pregnancy in $\geq 4 \mathrm{~cm}^{2} \mathrm{SCH}$. The continuation of pregnancy was seen more with $\mathrm{SCH}$ of size $<4 \mathrm{~cm}^{2}$.

Table 3. Maternal outcomes and perinatal outcomes

\begin{tabular}{|l|l|l|}
\hline $\begin{array}{c}\text { Maternal and perinatal } \\
\text { outcomes }\end{array}$ & Frequency & Percentage \\
\hline Spontaneous Abortion & 14 & 9.33 \\
\hline Term vaginal delivery & 102 & 75.00 \\
\hline Term CS & 18 & 13.23 \\
\hline Preterm Vaginal delivery & 11 & 8.08 \\
\hline Preterm CS & 5 & 3.67 \\
\hline APH & 20 & 14.70 \\
\hline IUGR & 25 & 18.38 \\
\hline LBW & 16 & 11.76 \\
\hline NICU admission & 19 & 13.97 \\
\hline
\end{tabular}

Table 4. Maternal Outcomes and SCH

\begin{tabular}{|c|c|c|c|c|c|}
\hline SCH & Term vaginal & Term CS & $\begin{array}{c}\text { Preterm } \\
\text { Vaginal }\end{array}$ & Preterm CS & APH \\
\hline$<4 \mathrm{~cm}^{2}$ & $90(66.17 \%)$ & $12(8.82 \%)$ & $08(5.88 \%)$ & $04(2.94 \%)$ & $12(8.82 \%)$ \\
\hline$\geq 4 \mathrm{~cm}^{2}$ & $12(8.82 \%)$ & $06(4.41 \%)$ & $03(2.20 \%)$ & $01(0.73 \%)$ & $08(5.88 \%)$ \\
\hline
\end{tabular}

Table 5. Association between maternal outcomes and $\mathrm{SCH}$

\begin{tabular}{|l|l|l|l|l|}
\hline \multirow{2}{*}{$\begin{array}{l}\text { Maternal } \\
\text { outcome }\end{array}$} & \multicolumn{2}{|c|}{$\mathrm{SCH}$} & \multirow{2}{*}{2 test } & $\begin{array}{c}P \\
\text { Value }\end{array}$ \\
\cline { 2 - 3 } $\begin{array}{l}\text { Spontaneous } \\
\text { Abortion }\end{array}$ & \multicolumn{2}{|c|}{1.903} & \multirow{2}{*}{0.179} \\
\hline Yes & 09 & 05 & & \\
\hline No & 109 & 27 & & \\
\hline APH & \multicolumn{2}{|c|}{5.404} & \multirow{2}{*}{0.033} \\
\hline Yes & 12 & 08 & & \\
\hline No & 96 & 20 & \\
\hline$\chi^{2}$ value was calculated by using Fisher's exact test \\
\hline
\end{tabular}

The association between $\mathrm{SCH}$ of size $\geq 4 \mathrm{~cm}^{2}$ and $\mathrm{APH}$ was found to be significant.

Table 6. Association between Perinatal outcomes and $\mathrm{SCH}$

\begin{tabular}{|c|c|c|c|c|}
\hline \multirow{2}{*}{$\begin{array}{c}\text { Fetal } \\
\text { outcome }\end{array}$} & \multicolumn{2}{|c|}{$\mathrm{SCH}$} & \multirow{2}{*}{$\chi^{2}$ test } & \multirow{2}{*}{ P Value } \\
\hline & $<4 \mathrm{~cm}^{2}$ & $\geq 4 \mathrm{~cm}^{2}$ & & \\
\hline \multicolumn{4}{|l|}{ IUGR } & \multirow{3}{*}{0.008} \\
\hline Yes & 15 & 10 & \multirow{2}{*}{$\begin{array}{l}7.060 \\
\text { (Pearson Chi } \\
\text {-square) }\end{array}$} & \\
\hline No & 93 & 18 & & \\
\hline \multicolumn{3}{|l|}{ LBW } & & \multirow{3}{*}{0.321} \\
\hline Yes & 11 & 05 & \multirow{2}{*}{$\begin{array}{c}1.261 \\
\text { (Fisher `s } \\
\text { exact test) }\end{array}$} & \\
\hline No & 97 & 23 & & \\
\hline \multicolumn{3}{|l|}{ NICU } & & \multirow{3}{*}{0.225} \\
\hline Yes & 13 & 06 & \multirow{2}{*}{$\begin{array}{c}1.632 \\
\text { (Fisher's exact } \\
\text { test) }\end{array}$} & \\
\hline No & 95 & 22 & & \\
\hline
\end{tabular}

The association between $\mathrm{SCH}$ of size $\geq 4 \mathrm{~cm}^{2}$ and IUGR was found to be significant whereas the association between $\mathrm{SCH}$ of size $\geq 4 \mathrm{~cm}^{2}$, NICU 
admission and Low birth weight were found to be insignificant.

\section{DISCUSSION}

Most of the cases in our study were in early reproductive age group with mean maternal age during presentation being $25.39 \pm 5.60$ years.

In our study, most women were primigravida (59.33\%). Various studies have different results. Study by Vashisth et $\mathrm{al}^{4}$ showed $51.90 \%$ primigravida and rest multigravida. Similarly, study by Sarmalkar et $\mathrm{al}^{5}$ had $52 \%$ primigravida and $48 \%$ multigravida women whereas study by Dongol et $\mathrm{al}^{6}$ concluded that most women were multigravida (54.3\%).

In our study, we found that cases with size of $\mathrm{SCH} \geq 4 \mathrm{~cm}^{2}$ had more risk of complications like spontaneous abortion, IUGR, APH and preterm labor as compared with $\mathrm{SCH}$ of size $<4 \mathrm{~cm}^{2}$. Similar findings were found in study by Jaishree Bamniya et $\mathrm{al}^{7}$.

The incidence of spontaneous abortion was $9.33 \%$ in our study which is similar to a retrospective study done among 516 patients by A. Ben Haroush et $\mathrm{al}^{8}$. The overall spontaneous abortion rate was $9.3 \%$. The size of $\mathrm{SCH}$ affected the rate of abortion, $18.8 \%$ in large size, $9.2 \%$ in moderate size and $7.7 \%$ in small size. In our study also, the rate of spontaneous abortion was $15.38 \%$ in $\mathrm{SCH}$ of size $\geq 4 \mathrm{~cm}^{2}$ and $8.06 \%$ in $\mathrm{SCH}$ of size $<4 \mathrm{~cm}^{2}$. However, Sarmalkar et $\mathrm{al}^{5}$ in 100 ladies had only 7\% spontaneous abortion which is less than ours. Similarly, study done by Agarwal et $\mathrm{al}^{9}$ found an incidence of $21 \%$ in 62 patients with history of threatened abortion in first 20 weeks of gestation. Our study has lesser rate of abortion which may be because all our cases had confirmed fetal viability on ultrasound.

Many studies have noted association between vaginal bleeding and preterm delivery. Batzofin et $\mathrm{al}^{10}$ and Williams et $\mathrm{al}^{11}$ have reported that the cases with vaginal bleeding had doubled the risk of preterm delivery as compared to cases without vaginal bleeding. Similarly, in study done by Wijesiriwardana et $\mathrm{al}^{12}$ there was significant association between the preterm delivery and threatened abortion. However, our study has found no association between preterm delivery and vaginal bleeding. Strobina et $\mathrm{al}^{13}$ also failed to show an association between preterm delivery and threatened abortion. This might be because our cases were treated with low dose aspirin and injection hydroxyprogesterone as support for prevention of progression of preterm delivery.

The risk of low birth weight in our study was $11.76 \%$ while study by Batzofin et $\mathrm{al}^{10}$ shows the incidence to be $15.48 \%$. Similarly, study by Davari Tanha et $\mathrm{al}^{14}$ also found the risk of LBW to be $14.9 \%$.

A study by Arafa et $\mathrm{al}^{15}$ reported an incidence of IUGR to be $48.5 \%$ while study by Davari Tanha et $\mathrm{al}^{14}$ revealed to be $2 \%$ whereas in our study, it was $18.38 \%$.

In our study, the association between the $\mathrm{SCH}$ with $\mathrm{APH}$ and IUGR were found to be significant which was similar to the results by Saraswat et $\mathrm{al}^{16}$ in which the systematic review observed that women with threatened abortion had significantly higher incidence of APH and IUGR.

Term delivery was seen in $88.23 \%$ of cases in our study. $75 \%$ had vaginal delivery while rest underwent Cesarean Section. A. Ben Haroush et $\mathrm{al}^{8}$ found the incidence of term delivery to be $86.5 \%$ which was similar to our study. Similarly, Dongol et $\mathrm{al}^{6}$ found the incidence of term delivery in cases of threatened abortion to be $75.8 \%$.

Our study had no cases of IUFD and PROM, however it was reported in many other studies. This might be due to regular follow up, progesterone support and addition of low dose 
aspirin. In study by Dongol et $\mathrm{al}^{6}$ reported three cases of IUFD out of 70 cases in their study and Sarmalkar et $\mathrm{al}^{5}$ found one case of IUFD in their study. Similarly, studies by Sarmalkar et $\mathrm{al}^{5}$ and Agrawal et $\mathrm{al}^{9}$ reported the incidence of PROM as high as $14 \%$ and $20.41 \%$ respectively.

\section{CONCLUSIONS}

Threatened abortion is a common phenomenon occurring during first and second trimester causing anxiety in pregnant women and their family members as it has been associated with poor maternal and fetal outcomes. Our study has shown association between IUGR and $\mathrm{APH}$ in threatened abortion with $\mathrm{SCH}$ of size $\geq$ $4 \mathrm{~cm}^{2}$ whereas no association between preterm delivery and NICU admission.

\section{ACKNOWLEDGEMENT}

We want to express our sincere gratitude to Dr. Alok Pradhan for helping in manuscript writing. We are forever grateful to our patients for trusting us and our study.

\section{REFERENCES}

\section{REFERENCES}

1. Cunningham FG, Gant NF, Leveno KJ, Gilstrap LC III, Health JC, Wenstrom KD. 21st ed. Williams obstetrics. New York: McGraw-Hill, 2001. P. 866-67.

2. Jouppila P. Clinical consequences after ultrasonic diagnosis of intra-uterine hematoma in threatened abortion. J Clin Ultrasound 1985;13:107 \pm 11 .

3. Weiss JL, Malone FD, Vidaver J, Ball RH, Nyberg DA, Comstock $\mathrm{CH}$, Hankins GD, Berkowitz RL, Gross SJ, Dugoff L, Timor-Tritsch IE. Threatened abortion: a risk factor for poor pregnancy outcome, a population-based screening study. American journal of obstetrics and gynecology. 2004 Mar 1;190(3):74550.

4. Vashisth N. A prospective study to determine the pregnancy and perinatal outcome in pregnant women presenting with first trimester vaginal bleeding. International Journal of Contemporary Medical Research 2020;7(12):L11-L15.

5. Sarmalkar MS, Singh S, Nayak AH. Maternal and perinatal outcome in

women with threatened abortion in first trimester. International Journal of Reproduction, Contraception, Obstetrics and Gynecology. 2016 May 1;5(5):143846.

6. Dongol A, Mool S, Tiwari P. Outcome of pregnancy complicated by threatened abortion. Kathmandu University Medical Journal. 2011;9(1):41-4.

7. Bamniya J, Shah H, Singh P, Doshi H, Shah M, Ladola H. Pregnancy outcome in patients with threatened abortion and abnormal early sonographic markers-A prospective study. International Journal of Biomedical and Advance Research. 2015;6(8):580-3.

8. Ben-Haroush A, Yogev Y, Mashiach R, Meizner I. Pregnancy outcome of threatened abortion with subchorionic hematoma: possible benefit of bedrest?. IMAJ-RAMAT GAN-. 2003 Jun $1 ; 5(6): 422-4$.

9. Agrawal S, Khoiwal S, Jayant K, Agarwal R. Predicting adverse maternal and perinatal outcome after threatened miscarriage. Open Journal of Obstetrics and Gynecology. 2013 Dec 26;2014. 
10. Batzofin JH, Fielding WL, Friedman EA. Effect of vaginal bleeding in early pregnancy on outcome. Obstetrics and gynecology. 1984 Apr 1;63(4):515-8.

11. Williams MA, Mittendorf RO, Lieberman EL, Monson RR. Adverse infant outcomes associated with first-trimester vaginal bleeding. Obstetrics and gynecology. 1991 Jul 1;78(1):14-8.

12. Wijesiriwardana A, Bhattacharya S, Shetty A, Smith N, Bhattacharya S. Obstetric outcome in women with threatened miscarriage in the first trimester. Obstetrics \& Gynecology. 2006 Mar 1;107(3):557-62.

13. Strobino B, Pantel-Silverman JU. Gestational vaginal bleeding and pregnancy outcome. American journal of epidemiology. 1989 Apr 1;129(4):806-15.

14. Davari TF, Shariat M, Kaveh M, Ebrahimi M, Jalalvand S. Threatened abortion: a risk factor for poor pregnancy outcome.

15. Arafa M. Outcomes of pregnancies complicated by early vaginal bleeding. EMHJ-Eastern Mediterranean Health Journal, 6 (2-3), 457-464, 2000. 2000.

16. Saraswat L, Bhattacharya S, Maheshwari A, Bhattacharya S. Maternal and perinatal outcome in women with threatened miscarriage in the first trimester: a systematic review. BJOG: An International Journal of Obstetrics \& Gynaecology. 2010 Feb;117(3):245-57.

Citation: Kayastha B, Shrestha A. Maternal and Perinatal Outcome of Threatened Abortion with Subchorionic Hemorrhage in First and Second Trimester. JCMS Nepal. $2021 ; 17(4) ; 316-21$. 